\title{
Assessing the Extent of ICT usage by Extension Professional for Sustainable Agriculture and Society in Sub Himalayan Region
}

\author{
C. Vara Prasad* and K. Pradhan
}

\author{
Department of Agricultural Extension, Uttar Banga Krishi Viswavidyalaya, Cooch Behar, \\ West Bengal, India \\ *Corresponding author
}

K e y w o r d s
$\begin{aligned} & \text { ICT and extension } \\ & \text { professional, Extent } \\ & \text { of ICT usage, ICT } \\ & \text { for agricultural } \\ & \text { development, Social } \\ & \text { sustainability, } \\ & \text { Sustainable } \\ & \text { livelihood }\end{aligned}$
$\begin{aligned} & \text { Article Info } \\ & \text { Accepted: } \\ & \text { 04 June } 2019 \\ & \text { Available Online: } \\ & \text { 10 July } 2019\end{aligned}$

A B S T R A C T

Information and Communication Technology (ICT) can be a key enabler and a vital component of the new knowledge-based economy and is capable of revolutionizing the process of information dissemination and knowledge management. In such a resilient backdrop, the present study attempts to assess the extent of ICT usage by an agricultural extension professional for guiding the farming community for sustainable agriculture development and restoring social sustainability. The present study was conducted in two northern districts of West Bengal under Sub Himalayan Region namely Cooch Behar and Alipurduar districts. The total number of respondents constitutes by eighty (80) extension professional which included extension personal from State Agriculture University, Krishi Vigyan Kendra, officials from State Department of Agriculture, input dealers and grassroot level extension staff from farmers clubs/ NGOs from these two districts, selected randomly for the present study. These extension professionals are interviewed through a pre-tested, structured interview schedule developed to measure the extent of ICT usage with the help of Google forms. The extent of ICT usage of the extension personal was considered as the predicted variable and sixteen other attributes were considered as the predictor variables for the study. The data were processed with the help of statistical tools like frequency, percentage, mean, standard deviation, correlation and weighted mean scoring for ranking the ICT tools. The result shows that among the attributes of extension professional the attributes namely social participation, aspiration towards cutting edge technology, annual income and annual expenditure are positively and significantly associated with 'Extent of ICT usage'. The result of the weighted mean score (WMS) analysis on the extent of ICT usage by agricultural extension professional in the study area have shown that Mobile phones $(m=3.97)$ which is ranked I, Internet $(m=2.62)$ which is ranked II, email $(\mathrm{m}=2.37)$ which is ranked III, Computer $(\mathrm{m}=2.13)$ which is ranked IV, TV/LCD $(m=2.1)$ which is ranked V, Digital camera $(m=1.45)$ which is ranked VI, LCD projector $(\mathrm{m}=1.29)$ which is ranked VII, printer $(\mathrm{m}=1.28)$ which is ranked VIII in terms of usage by extension professional.

\section{Introduction}

In the changing global scenario, agricultural development is surely information and knowledge sensitive. The development and growth of agriculture depend on the appropriate decision making along with strong information support. Social sustainability 
through the appropriate use of ICT in the agriculture sector is now the lime lighted discussion issues. The sustainable use of social resources through appropriate mobilisation of information in agriculture is always paving the new vistas for generation after generation as the Indian and Sub Himalayan societies mostly depend on agriculture for maintaining their livelihood status. The pluralistic informative extension approach, in the current scenario, is rapidly shifting globally and is recognised as an indispensable mechanism for saving knowledge (information) and advice as an input for modern farming and the use of ICT in actualizing so has made the involvement of practitioners (Richardson, 2003). The potential of ICTs for agriculture in the form of various portals were harnessed by agricultural developmental organisations like Government of India's Farmers portal- farmer.gov.in, agricultural marketing information network (AGMARKNET) for market informationagmarknet.gov.in, ITC's www.echoupal.comone of the largest initiative among all Internetbased interventions in rural India, agriwatch.com- a sophisticated agribusiness portal for achieving a perfect flow of information, analyses, communication and also e-commerce. And state governments have also taken initiatives to use the internet in various agricultural tasks like Gyandoot (Madhya Pradesh), e-Seva (Andhra Pradesh), Bhoomi (Land Record Computerisation), Raitha Samparka Kendra Online (Karnataka), Rasi, Miyams Karchipular (Tamil Nadu), and E-Srinkala (Kerala). According to Arkhi et al., (2008) considering the role of Extension in the Agricultural Information system as a connector between the farmers and the research centres, but the ground reality is hard-hitting with only one extension worker available for every 2879 farmers in India (Mukherjee and Maity, 2015), and on the other hand a recent survey conducted by National Sample Survey Office (NSSO) reported that only 41 per cent of the farm households received any assistance from either government or private extension services, and the government extension machinery covering only 11 per cent of the households who received extension assistance (Bera, 2014). In India, according to Adhiguru, et $a l$., in terms of accessing information sources, smallholder farmers relied primarily on progressive farmers $(16.7 \%)$ followed by input dealers $(13.1 \%)$, radio (13\%), television (9.3\%), newspapers (7\%) and extension worker $(5.7 \%)$. With these observations, it is worthwhile to mention that at the limited grassroots level extension personal with ICT support can play a major role in ensuring farmers' access to critical agricultural inputs as well as the information needs of the farmers in enhancing and sustaining the agricultural productivity and growth. This technology can act as a catalyst, by reducing the costs and by minimising the proximity among the villages and the farmers. ICT has a significant function in linking research, extension and the market toward expanding the professional and entrepreneurship abilities, capacities among the experts and the agricultural communities for sustainable agriculture and restoring social sustainability.

Keeping all these in view the present study has been envisaged to assessing the extent of ICT usage by extension professional for sustainable agriculture and society in Sub Himalayan Region.

\section{Materials and Methods}

Ex-post facto and exploratory research design were followed for this present study. It was conducted in two districts of Sub Himalayan Region namely Cooch Behar and Alipurduar districts. An exhaustive list of agriculture extension professional from two districts was prepared with the help of the department of agricultural extension, Cooch Behar KVK of 
Uttar Banga Krishi Viswavidyalaya and active farmers clubs in the study area. A total number of 80 extension professional, 50 from Cooch Behar district and 30 from Alipurdaur district were selected randomly for the present study which included extension personal from State Agriculture University, Krishi Vigyan Kendra, State Department of Agriculture officials, input dealers and grassroots level extension staff from farmers clubs/ NGOs. These eighty respondents were interviewed through a pre-tested structured interview schedule developed to measure the extent of ICT usage with the help of Google forms and data were collected from the respondents over mobile phones through a URL link sent to their smartphone. Variables age, education, experience, social participation, aspiration towards cutting edge technology, annual income, annual expenditure, smart gadgets possessing, sources of agricultural information, achievement motivation, innovativeness, economic motivation, scientific orientation, risk preference, orientation towards ICTs, information management orientation and the 'extent of ICT usage' of the extension professional was considered as the predicted variable for the study. The data were processed with the help of statistical tools like frequency, percentage, mean, standard deviation, weighted mean scores.

\section{Results and Discussion}

\section{Personal Profile of the Respondents}

Personal profile of the respondents has the basic information on age, education, experience, social participation, aspiration towards cutting edge technology, smart gadgets possessing and sources of agricultural information (Table 1).

Table 1 reveals that majority of the respondents belong to the age group 22-32 years renamed as young aged respondents
(43.8\%) followed by the age group 41-66 years renamed as old aged group respondents (28.8\%) and 33-40 years renamed as middleaged group $(27.4 \%)$. When it comes to the education of the respondents, it is clear that majority of the respondents are Graduates (45\%), followed by postgraduates $(30 \%)$ and high school $(25 \%)$. In terms of their experience, the majority of the respondents belong to a group of 1-6 years of low-level experience $(52.5 \%)$ followed by $13-30$ years group of high-level experience $(27.5 \%)$ and 712 years group of medium-level experience $(20.0 \%)$. From the above table it is also clear that majority of the respondents belong to the low level of social participation with membership in 1-2 institution/ organisation (55.0\%) followed high level with membership in 5-6 institutions/ organisations i.e. (31.2\%) and medium level of social participation with membership in 3-4 institutions/ organisations $(13.8 \%)$.

In the present study, aspiration towards cutting edge technologies revealed that the category of 27-30 score which represents the high level of aspiration towards ICTs is $46.7 \%$, followed by a low level of aspiration with 16-23 score are $28.8 \%$, and a medium level of aspiration with 24-26 score are $25.0 \%$. In case of smart gadgets the majority belong to the group of score 9-10 which represents high level in possessing the smart gadgets (57.4\%), followed by 7-8 score which represents medium level in possessing the smart gadgets (28.8\%), and 3-6 which represents low level in possessing the smart gadgets $(13.8 \%)$. Source of agricultural information among the respondents have shown that majority belong to the group of score 6-7 which represents a high source of agricultural information (43.8\%), followed by 4-5 score which represents a low source of agricultural information (28.8\%), and 1-3 which represents a low source of agricultural information (27.4\%). 
Table 2 presents the Pearson's coefficient of correlation among the dependent variable i.e. the extent of ICT usage and 16 causal variables for extension professional. The result shows that among the variables of extension professional; social participation, aspiration towards cutting edge technology, annual income and annual expenditure are positively and significantly associated with the extent of ICT usage.

Social participation and extent of ICT usage of respondents

Social participation of the respondents can be operationalized based on the nature of participation and the number of the organizations he/she participates in the social system. The present study revealed that even though the majority of the respondents belong to a low level of social participation, but nearly one-third of the respondents also possess a higher level of social participation. The possible reason may be that the higher the level of social participation, the more is the awareness of advanced technology in the society. This may be one of the reasons that social participation is contributing to characterizing the predicted variable 'extent of ICT usage'.

\section{Aspiration towards cutting edge technology and extent of ICT usage of respondents}

In the present scenario of technology-driven society, it is not surprised that the majority of the youth are fascinating towards aspiration towards cutting edge technology and rural youth are not an exception. The present study has shown that majority of the respondents are youth and have also shown a significant relation towards ICTs. They have the ability to use ICT tools and have a high level of access rather than the old aged extension personal. That is why the variable 'aspiration towards cutting edge technology' is significantly and positively contributing towards characterizing the predicted variable 'extent of ICT usage'.

\section{Annual income and extent of ICT usage of respondents}

The annual income of the respondents will directly reflect and influences the economic viability, stability and rational behaviour of an individual.

The probable reasons for having a positive and significant relationship of this variable with an extent of ICT usage is the fact that respondents with higher income groups have more awareness on the technological updates and also have a higher level of accesses to ICT tools and devices. That is why the variable 'annual income' is significantly and positively contributing towards characterizing the predicted variable 'extent of ICT usage' which is similar to the study of Kharmudai et al., (2018).

Annual expenditure and extent of ICT usage of respondents

Annual expenditure indicates the costs incurred annually in maintaining the farm and home for an individual family. Annual expenditure, in contrast to the annual income, stimulates an individual to identify the areas where the cost can be reduced by taking certain cost-saving strategies. In the present modern technological society, there is always a chance of increased cost.

But, increased cost always poses a barrier in the development of favourable attitude towards technology. Consequently, an increase in the expenditure of the individuals will ultimately reduce the interest in ICTs. That is why the variable annual expenditure is negatively and significantly contributing in the case of characterizing the predicted variable, the extent of ICT usage. 
Extent of ICT usage by extension professional $(\mathrm{N}=\mathbf{8 0})$

A perusal of Figure 1, shows that majority of the respondents i.e. 98 per cent are using mobile phones daily, followed by 2 per cent of them using weekly. In terms of connectivity i.e. internet utilisation, the majority are using fortnightly (49\%), followed by daily utilization $(40 \%)$ and $(1 \%)$ weekly. It is also found that there are 10 per cent of the respondents how are using a basic mobile phone with no internet connectivity. When it comes to email access majority (42\%) of the respondents are accessing their email fortnightly, followed by daily (36\%) and 3 per cent weekly. The study also revealed that 16 per cent of the respondents had no access to email and 3 per cent are not using email even though they have access to use. It is found from the study that majority of the respondents $(40 \%)$ are using computers fortnightly, followed by 30 per cent daily and the study also revealed that 20 per cent of the respondents are not possessing computers and 5 per cent are not using them even though they are available. It is found that 65 per cent of the respondents are using LCDs fortnightly for extension activities, followed by 11 per cent daily and 4 per cent weekly. It is also found that 11 per cent of the respondents are not possessing TV/LCD display and 9 per cent are not using even though they were possessing.

In evidence of the advanced technologies in the field of digital display, use of expensive LCD projectors are getting replaced by economical LED displays. And present study has also revealed the same that 45 per cent of the respondents reported non-availability and 19 per cent reported available, but not in use of LCD projectors and followed by fortnightly use 21 per cent, daily use 10 per cent and 5 per cent weekly. It is found that 40 per cent of the respondents are not possessing printers and 9 per cent reported not in use of printers even though they are available. With the advance of mobile phone technologies with in-built high definition cameras, the use of standalone cameras has come down in recent times. The present study also revealed the majority of the respondents (43\%) are not possessing and $(17 \%)$ are not using standalone cameras. The study revealed that 34 per cent of them are using camera fortnightly and very few i.e. 5 per cent of them are using daily and weekly.

\section{Weighted mean score}

$x=\frac{\sum_{i=1}^{n}\left(x_{i} * w_{i}\right)}{\sum_{i=1}^{n} w_{i}}$

Weighted mean score $(\mathrm{WMS})=\Sigma \mathrm{wx} / \Sigma \mathrm{W}$

$\Sigma=$ the sum of total

$\mathrm{w}=$ the weights.

$\mathrm{x}=$ the value.

The result of the weighted mean score (WMS) analysis in figure 2, on the extent of ICT usage by agricultural extension professional in the study area have showed that they use mobile phones $(\mathrm{m}=3.97)$, internet $(\mathrm{m}=2.62)$, email $(\mathrm{m}=2.37)$, computer $\quad(\mathrm{m}=2.13), \quad$ TV/LCD $(\mathrm{m}=2.1)$, Digital camera $(\mathrm{m}=1.45), \quad \mathrm{LCD}$ projector $(\mathrm{m}=1.29)$, printer $(\mathrm{m}=1.28)$ in their extension activity. The utilization of ICT tools by extension personal are ranked according to the weighted mean score, and the following ICT tools have been ranked in according to the weighted mean score.

\section{Mobile phones}

The mobile phone was found to be more utilized by extension personal with the WMS of 3.97 and ranked I. The probable reason for having high score is that irrespective of education, gender and economic status, the mobile phone has gained its popularity in terms of utilization across the social system. 
Table.1 Personal profile of the respondents $(\mathrm{N}=80)$

\begin{tabular}{|c|c|c|c|c|}
\hline S. No & Category & Frequency & Per cent & \\
\hline \multirow[t]{4}{*}{1.} & \multicolumn{3}{|l|}{ Age } & Range $=22-66$ \\
\hline & Young Aged (22-32) & 35 & 43.8 & Mean $=40.15$ \\
\hline & Middle Aged (33-40) & 22 & 27.4 & $\mathrm{SD}=12.54$ \\
\hline & Old Aged (41-66) & 23 & 28.8 & $\mathrm{CV}=31.23 \%$ \\
\hline \multirow[t]{4}{*}{2.} & \multicolumn{3}{|l|}{ Education } & Range $=5-7$ \\
\hline & High School & 20 & 25.0 & \multirow{3}{*}{$\begin{array}{l}\text { Mean }=6.05 \\
S D=0.74 \\
C V=12.30 \%\end{array}$} \\
\hline & Graduate & 36 & 45.0 & \\
\hline & Post Graduate & 24 & 30.0 & \\
\hline \multirow[t]{4}{*}{3.} & \multicolumn{3}{|l|}{ Experience } & Range $=1-30$ \\
\hline & Low (1-6 years) & 42 & 52.5 & Mean $=9.20$ \\
\hline & Medium (7-12 years) & 16 & 20.0 & $\mathrm{SD}=7.98$ \\
\hline & High (13-30 years) & 22 & 27.5 & $\mathrm{CV}=86.75 \%$ \\
\hline \multirow[t]{4}{*}{4.} & \multicolumn{3}{|l|}{ Social Participation } & Range $=1-6$ \\
\hline & Low (1-2) & 44 & 55.0 & Mean $=3.02$ \\
\hline & Medium (3-4) & 11 & 13.8 & $\mathrm{SD}=2.12$ \\
\hline & High (5-6) & 25 & 31.2 & $\mathrm{CV}=70.17 \%$ \\
\hline \multirow[t]{4}{*}{5.} & \multicolumn{3}{|c|}{ Aspiration towards technologies } & Range $=16-30$ \\
\hline & Low $(16-23)$ & 23 & 28.8 & Mean $=25.18$ \\
\hline & Medium (24-26) & 20 & 25.0 & $\mathrm{SD}=4.25$ \\
\hline & High (27-30) & 37 & 46.2 & $\mathrm{CV}=16.89 \%$ \\
\hline \multirow[t]{4}{*}{6.} & \multicolumn{3}{|c|}{ Smart gadgets possessing } & Range $=3-10$ \\
\hline & Low (3-6) & 11 & 13.8 & Mean $=8.35$ \\
\hline & Medium (7-8) & 23 & 28.8 & $\mathrm{SD}=2.01$ \\
\hline & High $(9-10)$ & 46 & 57.4 & $C V=24.13 \%$ \\
\hline \multirow[t]{4}{*}{7.} & \multicolumn{3}{|c|}{ Source of Agriculture Information } & Range $=1-7$ \\
\hline & Low (1-3) & 22 & 27.4 & Mean $=4.90$ \\
\hline & Medium (4-5) & 23 & 28.8 & $\mathrm{SD}=2.02$ \\
\hline & High (6-7) & 35 & 43.8 & $\mathrm{CV}=41.22 \%$ \\
\hline
\end{tabular}

Table.2 Correlation coefficient of extent of ICT usage with 16 independent variables

\begin{tabular}{|c|c|}
\hline Variables & Correlation Coefficient (r) \\
\hline Age $\left(X_{1}\right)$ & -0.136 \\
\hline Education $\left(\mathbf{X}_{2}\right)$ & 0.072 \\
\hline Experience $\left(\mathbf{X}_{3}\right)$ & -0.098 \\
\hline Social Participation $\left(\mathbf{X}_{4}\right)$ & $0.420 * *$ \\
\hline Aspiration towards cutting edge technology $\left(\mathrm{X}_{5}\right)$ & $0.262 *$ \\
\hline Annual Income $\left(X_{6}\right)$ & $0.316 * *$ \\
\hline Annual Expenditure $\left(\mathbf{X}_{7}\right)$ & $0.308^{*}$ \\
\hline Smart Gadgets possessing $\left(\mathbf{X}_{8}\right)$ & 0.097 \\
\hline Sources of Agricultural Information $\left(\mathrm{X}_{9}\right)$ & 0.118 \\
\hline Achievement Motivation $\left(\mathrm{X}_{10}\right)$ & -0.172 \\
\hline Innovativeness $\left(\mathrm{X}_{11}\right)$ & 0.009 \\
\hline Economic Motivation $\left(\mathrm{X}_{12}\right)$ & 0.147 \\
\hline Scientific Orientation $\left(\mathbf{X}_{13}\right)$ & -0.165 \\
\hline Risk Preference $\left(\mathbf{X}_{14}\right)$ & -0.147 \\
\hline Information Management Orientation $\left(\mathrm{X}_{15}\right)$ & -0.122 \\
\hline Orientation towards ICTs $\left(\mathrm{X}_{16}\right)$ & 0.152 \\
\hline \multicolumn{2}{|l|}{$* *$. Correlation is significant at the 0.01 level } \\
\hline *. Correlation is significant at the 0.05 level & \\
\hline
\end{tabular}



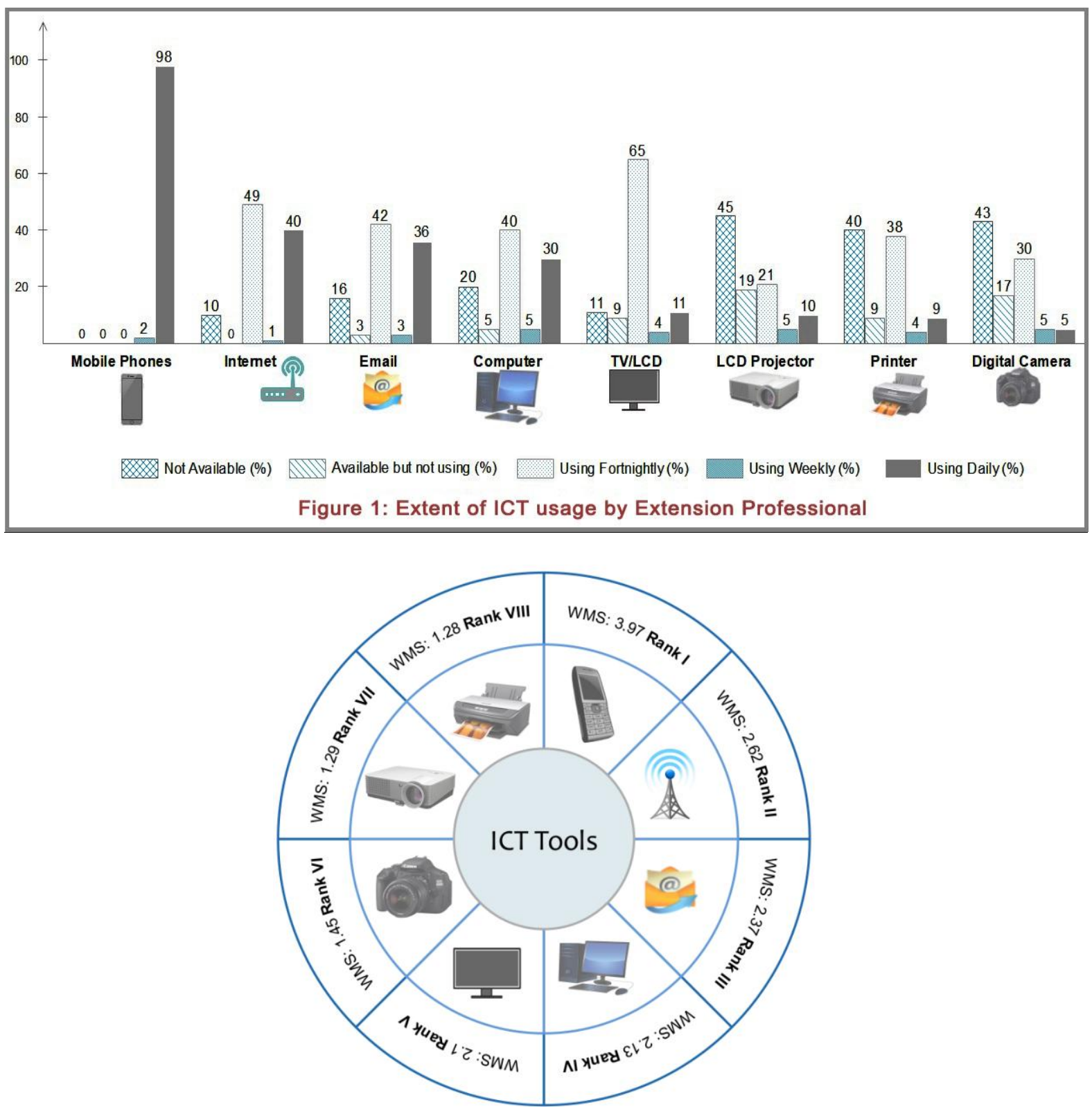

Figure 2: Weighted Mean Score (WMS) of ICT tools used by Extension Professional

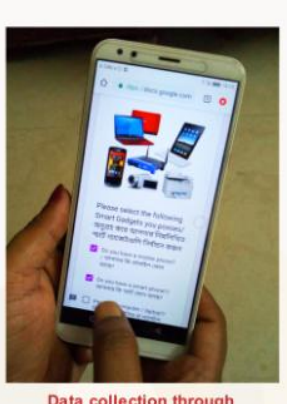

Data collection through Smart Phone

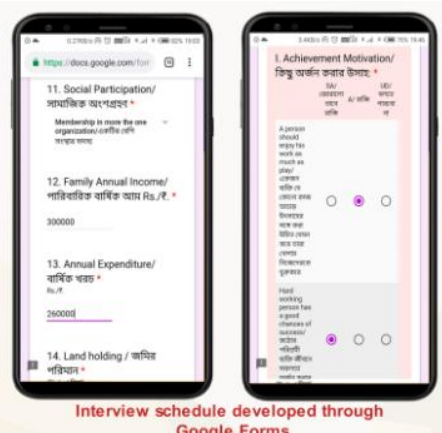

Google Forms 
The interesting thing about the mobile phone is that it is mobile friendly in nature and userfriendly coupled with other additional features like built-in camera, high-speed internet facility, email, GPS, word processors and many more. It is clear that extension personnel are shifting their use of ICT tools towards such mobile friendly and user-friendly technologies.

\section{Internet}

The percentage of individuals accessing the internet in the country has increased from 10 to 29.55 in 2014 to 2018 respectively (TII). The launch of $4 G L T E$ service by a service provider in September 2016 provides wireless service to customers at a very low price.

The service provider announced that it had acquired 16 million subscribers within the first month of commercial operation and crossed 50 million subscribers in record 83 days and by October 2017 it had about 130 million subscribers (Md. Thayyib).

With these dramatic changes in the telecom sector, and with a heavy competition within the sector, the internet tariffs have come down which ultimately increased in a number of users. These may be the major reason for the increase in the internet utilization and for the WMS of 3.97 which stood ranked II.

\section{Email}

Along with the increase in the e-connectively, email as a paperless communication has gained its popularity in penetrating into the communication space.

Wijekoon (2004) Stated that government researchers and extension workers based in rural villages can communicate with colleagues and experts in seconds rather in days and communication by emails is the fastest mailing service available for extension personal in this information age. These may be the major reason for the increase in the email utilization with a WMS of 2.37 which stood ranked III.

\section{Computer}

Even though 40 per cent are using computers fortnightly and 30 per cent daily around onefourth of the extension personal have no access to the computer. Based on the weighted mean score $(m=2.13)$ use of computers by extension personal is ranked IV. The possible reason for this is, non-availability of computers on one side and low computer literacy on the other side. A study conducted by Agha et al., in the northern part of India has revealed that only 23.3 per cent of the extension personal are using the computer for advisory work such as an expert system of different crops. And felt that still there is a need to exploit more by field functionaries to increase outreach.

\section{TV/LCD}

It is found that 65 per cent of the respondents are using LCDs fortnightly for extension activities and 11 per cent using them daily for a various extension activity, during farmers training programmes and promotional activities. In evidence of the advanced technologies in the field of digital display, many of the extension personal have shifted to LCD TVs form LCD projector. The possible reason for this is due to the relative advantage of LCD TVs over LCD projectors i.e. they can be used during day time and do not require to make the room dark. And LCD TVs have become economical compared to LCD projectors. That is why the ICT tool LCD TVs have scored $(\mathrm{m}=2.1)$ which has ranked $\mathrm{V}$.

\section{Digital Camera}

Digital Camera was found to be very low utilized ICT tool by the extension personal with the WMS of 1.45 and ranked VI. Documentation of the extension activities is one of the important procedure which helps in understanding the whole activity. And the use of a digital camera was found to be the best option for documentation purpose. But with the advance of mobile phone technologies with inbuilt high definition cameras, the use of digital 
cameras has come down in recent times. The present study has also revealed that the majority of the respondents $(43 \%)$ are not possessing and $(17 \%)$ are not using cameras even though it is an available and smartphone with high definition camera are used during the extension activity by extension personal. This may be the possible reason that use of the digital camera has come down.

\section{LCD projector}

In the present study, the use of LCD projectors for agricultural extension was found to be very low by the extension personal with the WMS of 1.29 which ranked VII. Basically audio-visual aids are one of the most effective means of ICT tools and are used for various extension activities especially for video projection. One of the organisations says "Now, a handheld Pico Projector (mini projector) with videos in it had replaced the flip charts and pen and paper". But; in evidence of the advanced technologies in the field of digital display, use of expensive LCD projectors are getting replaced by economical LCD/LED displays. And present study has also revealed the same that 45 per cent of the respondents reported non-availability and 19 per cent reported available, but not in use of LCD projectors.

\section{Printer}

From the present study, it is evident that the use of printers for extension activities is found to be very low i.e. nearly half of the respondents have no access to the printers and it is found that only 9 per cent of them are daily using the printer for various office workers but not for extension purpose. This is the reason why the printer has scores last with WMS of 1.28 which ranked VIII

In the present digital era where information and communication technology (ICT) tools like computers, smartphones and other digital tools are emerging as a vital component of new technology and knowledge-based community. In such digital economy where ICTs tools are changing mode of accessing knowledge and breaking the barriers and the Government of India flagship initiatives like Digital India programme with a vision to transform India into a digitally empowered society and knowledge economy, ICT driven extension services are going to play key role in accessing the information and knowledge sharing among the actors of the knowledge generation, knowledge dissemination, input supply and knowledge consumption systems holistically. To conclude, the Sub Himalayan Region of India is primarily dominated by agrarian society. The agricultural development and sustainability in food security purely depend upon agricultural productivity enhancement and producers' income enhancement. Towards this direction, the agricultural society is moving towards the knowledge vibrant and information intensive social change in the agricultural sector to restore social sustainability. The young generation is trying to indulge themselves in agriculture as the digital ICT tools are making themselves equipped with the updated agricultural information which in turn restricts the social entropy, social income imbalance. The social sustainability through agricultural sustainability by enhancing agricultural profitability by appropriate use of ICT tools through extension professional usher a new era of digital agriculture. Still, the study identified some of the backdrops to achieve the same within a short period of time as it is a long term interaction and interface between the society and ICT usage in an appropriate manner. The study identified the most effective ICT tool among the extension agents namely the telephonic expert solutions through high end smart mobile phones which is really impacting upon the society like anything towards social sustainability.

The study also revealed for developing the extension policy strategies by changing the extension paradigm from conventional pluralistic extension system to digital extension system to reach the unreached within a short period of time by considering the psycho-social attributes of extension agents through 
enhancement of their earning or salary and compensation to use ICT tools, providing training to facilitate their aspiration levels for using ICT tools towards cutting edge technology etc.

By large it would not be exaggerative to utter that the information-intensive agriculture towards enhancing the profitability of the farming community definitely depends upon the digital literacy and appropriate use of ICT tools by the extension change agents to reach the digitally vibrant agricultural and social sustainability in Sub Himalayan Region of India.

\section{References}

Adhiguru P., Birthal P.S. and Ganesh Kumar B. (2009) Agricultural Economics Research Review, 22, 71-79.

Arkhi, S., E. Darvishi and M. Adibnejad (2008). The role of ICT in agricultural extension and education and natural resources to attained sustainable development. The first national conference of agricultural management and sustainable development.

Bera, S. (2014). Nearly 52\% agricultural households indebted, shows NSSO survey. $\quad$ http://www.livemint. com/Politics/ZFPXWN8hdAAUb49jV12 NqK/Nearly-52-agricultural-householdsindebted-shows-NSSOsurv.html. (Updated on 20 December, 2014; Accessed on 10. May, 2019).

Kharmudai A., D. Sumi. Jyothi S.S.P (2018).
Attitude of Tribal Farmers of Meghalaya towards ICT-Based Extension Services. Indian Journal of Hill Farming, Special Issue, Page 71-75,

Muhammed Thayyib. K, (2018). The Impact of Jio on Indian Telecom Industry. International Journal of Research in Management, Economics and Commerce, Vol. 08, Issue 04, April 2018, Page 78-82.

Mukherjee, A. and Maity, A. (2015). Publicprivate partnership for convergence of extension services in Indian agriculture. Current Science, 109(9): 1557-1563.

Noor Agha, B.S. Ghanghas and Chahal, P.K. 2018. Use of Information and Communication Technologies by Extension Personnel to Disseminate Agricultural Information. Int. J. Curr. Microbiol. App. Sci. 7(04): 1369-1376

Richardson, D. (2003). Agricultural extension transforming ICTs? Championing universal access ICT observatory 2003: ICTs transforming agricultural extension Wageningen, 23-25 September 2003. Wageningen: CTA.

Telecommunication Infrastructure Index (TII) and its components, (2018). United Nations E-Government Survey 2018, Gearing E-Government to Support Transformation Towards Sustainable And Resilient Societies, P 252

Wijekoon, Rohan. (2004). Wireless cyber extension: An ICT initiative to rural farmers in Srilanka, Role of ICT for poverty alleviation through agriculture development in SAARC countries held at Dhaka, Bangladesh.

\section{How to cite this article:}

Vara Prasad, C. and Pradhan, K. 2019. Assessing the Extent of ICT usage by Extension Professional for Sustainable Agriculture and Society in Sub Himalayan Region. Int.J.Curr.Microbiol.App.Sci. 8(07): 142-151. doi: https://doi.org/10.20546/ijcmas.2019.807.018 